\title{
SUPER- JA THOMASFOSFAATTI RAHKASUON LANNOITTEINA
}

\author{
MaUri TAKala \\ Suoviljelysyhdistys, Leteensuon koeasema
}

Saapunut 20. 4. 1961

Monet viljelytoimenpiteet rahkasoilla on järjestettävä eri tavalla kuin muilla maalajeilla. Kun rahkasuot ovat happamia ja käytettävän fosfaattilannoitelajin on selitetty riippuvan ratkaisevasti muun muassa maan happamuudesta, lienee paikallaan tarkastella rahkasoiden fosfaattilannoitusta erään Leteensuon kokeen perusteella. Näitä tuloksia on VESIKIVI (7) jo aikaisemmin selostanut yksityiskohtaisesti vuosien 1926-1937 ajalta.

Vuonna 1926 aloitetun kokeen on perustanut A. Vesikivi. Sitä ovat hoitareet A. Vesikivi (1926-1943), J. Törmä (1944), U. E. Hirvensalo (1945-1946) ja A. Isotalo (1947-1952).

\section{Koemaa}

Yksityiskohtaisen kasvipeitekuvauksen suoalueesta on tehnyt LINDBERG (2). Suon geologista puolta on selvittänyt Rindell (5). Koealue on luonnontilassa ollut rahkarämettä. Maatumatontạ rahkaturvetta on noin $2 \mathrm{~m}$. Tämän kerroksen alla on rahkasara- ja saraturvetta. Koko turvekerroksen syvyys on yli $3 \mathrm{~m}$.

Alue on raivattu viljelykselle kuokkimalla kesällä 1924 ja savettu kevättalvella $1926\left(200 \mathrm{~m}^{3} / \mathrm{ha}\right)$. Se on ojitettu avo-ojilla $20 \mathrm{~m}: \mathrm{n}$ sarkoihin. Koe on sijoitettu kahdelle saralle. Vuosina 1926-1927 koealue on lannoitettu karjanlannalla ja suomudalla, puoliksi kumpaakin, yht. $50 \mathrm{~m}^{3} / \mathrm{ha}$. Lannoitus on uudistettu samalla määrällä v. 1935. Toinen sarka on kalkittu käyttäen sammutettua kalkkia vv. $1926-19274000 \mathrm{~kg} / \mathrm{ha}$, v. $19352000 \mathrm{~kg} / \mathrm{ha}$ ja v. 1940 kalkkikivijauhetta 2000 $\mathrm{kg} / \mathrm{ha}$.

Muokkaus ja muut hoitotoimenpiteet on suoritettu samalla tavalla kuin talousviljelyksillä. 
Koesuunnitelma on seuraava:

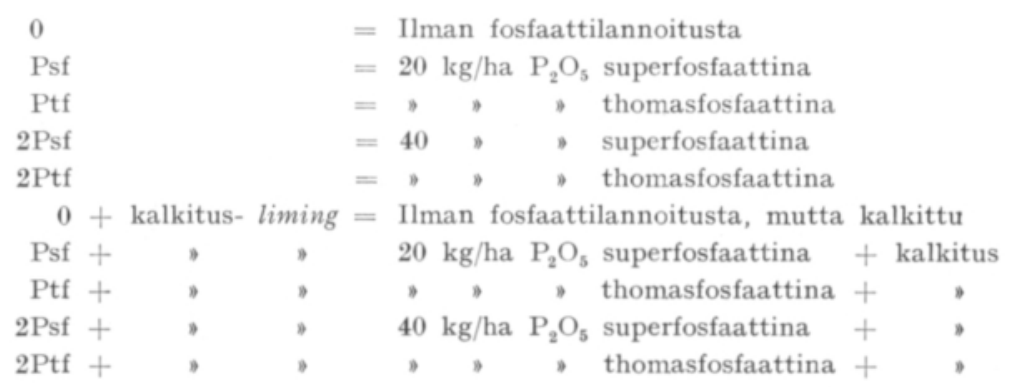

Käytetyt thomasfosfaattimäärät sisälsivät sitruunahappoon liukenevaa $\mathrm{P}_{2} \mathrm{O}_{5}$ :ttä yhtä paljon kuin vertailtavat superfosfaattimäärät sisälsivät ammoniumsitraattiin liukenevaa $\mathrm{P}_{2} \mathrm{O}_{5}$ :ttä. Kaikki koejäsenet ovat saaneet vuosittain $100 \mathrm{~kg} / \mathrm{ha} \mathrm{K}_{2} \mathrm{O}$ $40 \%$ :na kalisuolana ja $200-300 \mathrm{~kg} /$ ha kalkkisalpietaria.

Alkuperäiseen koesuunnitelmaan on tehty kokeen loppuajalla seuraavat muutokset: V. 1940 ja v. 1942 sekä vv. 1949-1952 ei annettu fosfaattilannoitteita ollenkaan. V. 1948 thomasfosfaatti korvattiin vastaavalla määrällä hienofosfaattia. Koetulokset vuodesta 1948 alkaen esitetään erillisinä taulukossa 5 .

Koealueella on viljelty heinää, kauraa ja hernekauraa. Vain yhtenä vuotena on viljelty ruista. Heinänsiemenseoksissa on käytetty $\mathrm{n} .10 \mathrm{~kg} / \mathrm{ha}$ puna- ja alsikeapilaa sekä n. $30 \mathrm{~kg} / \mathrm{ha}$ timoteita. Siemenseosten perusteella on ollut mahdollista saada apilarikkaita nurmia. Yhtenä vuotena on koealue ollut kesantona ja koetulokset puuttuvat kolmelta vuodelta. Heinä- ja olkisadot on ilmoitettu ilmakuivina, jyväsadot kuivattuina.

\section{Satotulokset}

Koevuosien sääolot ilmenevät eräästä aikaisemmasta PESSIN (3) tutkimuksesta.

Kokeen vuotuiset satotulokset nähdään liitetaulukosta I.

\section{Nurmet}

Taulukosta 1 ilmenee, että superfosfaatti on ollut selvästi thomasfosfaattia parempi lannoite. Ero on kaksinkertaisia fosfaattimääriä käytettäessä ollut selvempi kuin yksinkertaisilla määrillä ja erittäin selvä kalkitulla koealueella. Tulokset ovat rinnastettavissa eräässä mutasuolle järjestetyssä vastaavanlaisessa kokeessa saatuihin tuloksiin (6). 
Taulukko 1. Keskimääräiset heinäsadot vuotta kohden $\mathrm{kg} / \mathrm{ha}(9 \mathrm{v})$.

Table 1. Average annual yields of hay $\mathrm{kg}$ per ha (9 years).

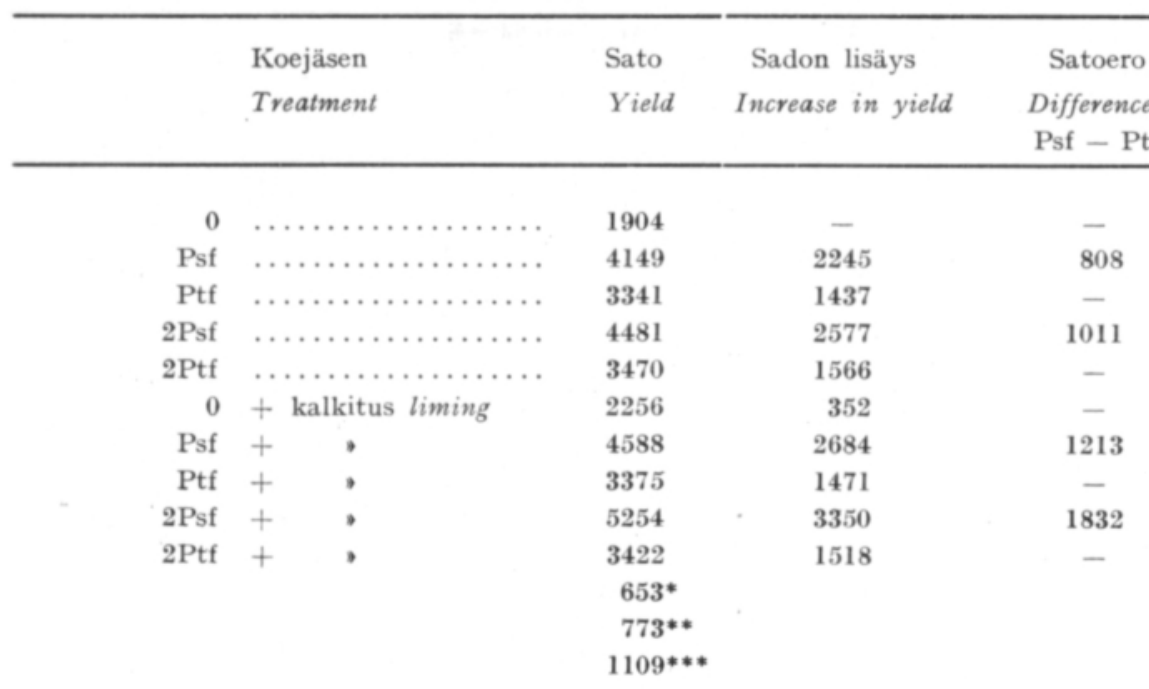

\section{Viljat}

Kauran ja hernekauran satotulokset esitetään taulukoissa 2 ja 3 . Rukiin osalta tulokset selviävät liitetaulukosta I. Taulukoista ilmenee, että superfosfaatti on viljan viljelyssäkin ollut yleensä thomasfosfaattia parempi, joskin erot ovat pienemmät kuin heinällä. Tähän vaikuttanee se, että lannoitteet on mullattu maahan.

Taulukko 2. Keskimääräiset kauran jyvä- ja olkisadot vuotta kohden kg/ha (4 v).

Table 2. Average grain and straw yields of oats $\mathrm{kg}$ per ha (4 years).

\begin{tabular}{|c|c|c|c|c|c|}
\hline & $\begin{array}{l}\text { Koejäsen } \\
\text { Treatment }\end{array}$ & $\begin{array}{l}\text { Jyväsato } \\
\text { Crop yield }\end{array}$ & $\begin{array}{c}\text { Sadon lisãys } \\
\text { Increase in yield }\end{array}$ & $\begin{array}{c}\text { Satoero } \\
\text { Difference } \\
\text { Psf - Ptf }\end{array}$ & $\begin{array}{l}\text { Olkisato } \\
\text { Straw } \\
\text { yield }\end{array}$ \\
\hline $\mathbf{0}$ & $\ldots \ldots \ldots \ldots \ldots \ldots \ldots$ & 1092 & - & - & 1989 \\
\hline Psf & $\ldots \ldots \ldots \ldots \ldots \ldots$ & 1627 & 535 & 106 & 2788 \\
\hline Ptf & $\ldots \ldots \ldots \ldots \ldots \ldots$ & 1521 & 429 & - & 2544 \\
\hline 2 Psf & $\ldots \ldots \ldots \ldots \ldots \ldots$ & 1714 & 622 & 252 & 2942 \\
\hline $2 \mathrm{Ptf}$ & $\ldots \ldots \ldots \ldots \ldots \ldots$ & 1462 & 370 & - & 2637 \\
\hline 0 & + kalkitus liming & 970 & -122 & - & 1711 \\
\hline Psf & $+\quad \cdot$ & 1457 & 365 & 276 & 2467 \\
\hline Ptf & + & 1181 & 89 & - & 1976 \\
\hline 2Psf & + & 1537 & 445 & 263 & 2633 \\
\hline $2 \mathrm{Ptf}$ & + & $\begin{array}{c}1274 \\
196^{*} \\
265^{* *} \\
352^{* * *}\end{array}$ & 182 & - & 2262 \\
\hline
\end{tabular}


Taulukko 3. Keskimääräiset herne-kauran jyvä- ja olkisadot vuotta kohden $\mathrm{kg} / \mathrm{ha}(4 \mathrm{v})$.

Table 3. Average grain and straw yields of mixed peas and oats $\mathrm{kg}$ per ha (4 years).

\begin{tabular}{|c|c|c|c|c|c|}
\hline & $\begin{array}{l}\text { Koejäsen } \\
\text { Treatment }\end{array}$ & $\begin{array}{l}\text { Jyväsato } \\
\text { Crop yield }\end{array}$ & $\begin{array}{l}\text { Sadon lisäys } \\
\text { Increase in yield }\end{array}$ & $\begin{array}{l}\text { Satoero } \\
\text { Difference } \\
\text { Psf - Ptf }\end{array}$ & $\begin{array}{c}\text { Olkisato } \\
\text { Straw } \\
\text { yield }\end{array}$ \\
\hline 0 & $\ldots \ldots \ldots \ldots \ldots \ldots$ & 1628 & - & - & 3203 \\
\hline Psf & $\ldots \ldots \ldots \ldots \ldots \ldots \ldots$ & 1933 & 315 & -70 & 3640 \\
\hline Ptf & $\ldots \ldots \ldots \ldots \ldots \ldots \ldots$ & 2003 & 385 & - & 3770 \\
\hline 2Psf & $\ldots \ldots \ldots \ldots \ldots \ldots \ldots$ & 1997 & 379 & 11 & 3867 \\
\hline $2 \mathrm{Ptf}$ & $\ldots \ldots \ldots \ldots \ldots \ldots \ldots$ & 1986 & 368 & - & 3788 \\
\hline 0 & + kalkitus liming & 1640 & 22 & - & 3378 \\
\hline Psf & $+\quad$. & 2086 & 468 & 138 & 4055 \\
\hline Ptf & + & 1948 & 330 & - & 3812 \\
\hline 2Psf & + & 2146 & 528 & 53 & 4226 \\
\hline \multirow[t]{4}{*}{$2 \mathrm{Ptf}$} & + & 2093 & 475 & - & 4104 \\
\hline & & $310^{*}$ & & & \\
\hline & & $418 * *$ & & & \\
\hline & & $557 * * *$ & & & \\
\hline
\end{tabular}

\section{Yhdistelmä kaikkien koekasvien sadoista}

Suoritettaessa tulosten tarkastelua rehuyksikköarvojen perusteella on ryarvoina käytetty: heinä 0.4 , kaura ja hernekaura 0.8 , ruis 1.0 ja oljet 0.27 .

Taulukosta 4 ilmenee, että koko koeajan kuluessa on superfosfaatti antanut parempia satoja kuin thomasfosfaatti. Kalkitulla koealueella on superfosfaatin vaikutus ollut huomattavasti suurempi kuin kalkitsemattomalla.

Taulukko 4. Keskimääräiset sadot $\mathrm{ry} / \mathrm{ha}$ (18 vuotta).

Table 4. Average yields of all experimental plants during the entire test period (18 years) food units per ha.

\begin{tabular}{|c|c|c|c|c|}
\hline & $\begin{array}{l}\text { Koejäsen } \\
\text { Treatment }\end{array}$ & $\begin{array}{l}\text { Sato } \\
\text { Yield }\end{array}$ & $\begin{array}{c}\text { Sadon lisäys } \\
\text { Increase in yield }\end{array}$ & $\begin{array}{c}\text { Satoero } \\
\text { Difference } \\
\text { Psf - Ptf }\end{array}$ \\
\hline 0 & $\ldots \ldots \ldots \ldots \ldots \ldots$ & 1248 & - & \\
\hline Psf & $\ldots \ldots \ldots \ldots \ldots \ldots$ & 1970 & 722 & +190 \\
\hline Ptf & $\ldots \ldots \ldots \ldots \ldots \ldots$ & 1780 & 532 & \\
\hline $2 \mathrm{Psf}$ & $\ldots \ldots \ldots \ldots \ldots \ldots$ & 2085 & 837 & +288 \\
\hline $2 \mathrm{Ptf}$ & $\ldots \ldots \ldots \ldots \ldots$ & 1797 & 549 & \\
\hline 0 & + kalkitus liming & 1269 & 21 & \\
\hline Psf & , & 2043 & 795 & +397 \\
\hline Ptf & - & 1646 & 398 & \\
\hline 2Psf & - & 2233 & 985 & +489 \\
\hline $2 P t f$ & $\ldots \ldots \ldots \ldots \ldots \ldots$ & 1744 & 496 & \\
\hline F-arve & : väkilannoitteet $413.4^{* * *}$ & kalkitus & $344.2 * * *$ & \\
\hline \multicolumn{2}{|c|}{ F-value: artificial fertilization } & liming & & \\
\hline merkit & tsevä ero $\quad 48.0^{*}$ & & $30.3^{*}$ & \\
\hline \multicolumn{2}{|c|}{ sign. diff. } & & $40.3^{* *}$ & \\
\hline & $83.0 * * *$ & & $52.4 * * *$ & \\
\hline
\end{tabular}




\section{Jälkivaikutus}

Kuten jo edellä on selostettu, muutettiin thomasfosfaatti v. 1948 hienofosfaatiksi ja senjälkeen fosfaattilannoitus jätettiin kokonaan pois, mutta NKlannoitus annettiin. Tulokset on esitetty taulukossa 5. Taulukosta ilmenee, että thomasfosfaatin ja hienofosfaatin jälkivaikutus on ollut yleensä parempi kuin superfosfaatin, joskaan erot eivät ole tilastollisesti merkitseviä.

Taulukko 5. Fosfaattilannoitteiden jälkivaikutus.

Table 5. After effect of phosphate fertilizers.

\begin{tabular}{|c|c|c|c|c|}
\hline \multicolumn{2}{|r|}{ Koejäsen } & \multirow{2}{*}{$\begin{array}{c}\text { Kauran jyväsato } \\
\mathrm{kg} / \mathrm{ha} \text { v. } 1948 \\
\text { Crop of oats } \\
\mathrm{kg} / \mathrm{ha}, 1948\end{array}$} & \multirow{2}{*}{$\begin{array}{l}\text { Keskimääräinen } \\
\text { heinäsato } \mathrm{kg} / \mathrm{ha} \\
\text { vv. } 1949-1951 \\
\text { Average crop of } \\
\text { hay } \mathrm{kg} / \mathrm{ha}, \\
1949-1951\end{array}$} & \multirow{2}{*}{$\begin{array}{c}\text { Kauran jyväsato } \\
\mathrm{kg} / \mathrm{ha}, \mathrm{v} .1952 \\
\text { Crop of oats } \\
\mathrm{kg} / \mathrm{ha}, 1952\end{array}$} \\
\hline & Treatment & & & \\
\hline 0 & $\ldots \ldots \ldots \ldots \ldots \ldots \ldots$ & 1700 & 460 & 630 \\
\hline Psf & $\ldots \ldots \ldots \ldots \ldots \ldots \ldots$ & 2470 & 1267 & 1020 \\
\hline $\mathrm{Ptf}$ & $\ldots \ldots \ldots \ldots \ldots \ldots$ & 2410 & 1707 & 1250 \\
\hline 2Psf & $\ldots \ldots \ldots \ldots \ldots \ldots$ & 2810 & 2263 & 2030 \\
\hline $2 \mathrm{Ptf}$ & $\ldots \ldots \ldots \ldots \ldots \ldots$ & 2480 & 2683 & 1990 \\
\hline 0 & + kalkitus liming & 1590 & 913 & 700 \\
\hline Psf & $+\quad$. & 2400 & 2310 & 1170 \\
\hline Ptf & + & 2150 & 2670 & 1480 \\
\hline 2Psf & + & 2720 & 4333 & 1770 \\
\hline \multirow[t]{4}{*}{$2 \mathrm{Ptf}$} & + & 2270 & 4310 & 2130 \\
\hline & & & $1258^{*}$ & \\
\hline & & & $1724 * *$ & \\
\hline & & & $2375 * * *$ & \\
\hline
\end{tabular}

Fosfaattilannoituksen ja kalkituksen yhteisvaikutus

Tutkittaessa edellä esitettyjen taulukoiden perusteella fosfaattilannoitteiden ja kalkituksen yhteisvaikutusta havaitaan superfosfaatin ja kalkituksen yhteisvaikutuksen olevan positiivisen, lukuunottamatta kauraa, jolla molempien fosfaattilannoitteiden ja kalkituksen yhteisvaikutus on negatiivinen. Kalkituksen satoa alentava vaikutus kauralla on todettu useissa muissakin Leteensuon rahkasuoviljelyksillä suoritetuissa kokeissa (4). Heinällä molemmat thomasfosfaattimäärät, hernekauralla pienempi thomasfosfaattimäärä ja kaikilla koekasveilla suurempi thomasfosfaattimäärä, ovat kalkituksen kanssa aiheuttaneet negatiivisen yhteisvaikutuksen.

\section{Sadon laatu}

VESIKIVI (7) on tutkiessaan esillä olevan kokeen sadon laatua botaanisten heinäanalyysien avulla havainnut superfosfaattilannoituksen lisäävän apilan määrää nurmessa varsinkin kalkitulla alueella. Myös kalkitus lisäsi heinän apilapitoisuutta. 
Kalkitus ja fosfaattilannoitus lisäsivät hernekaurasatojen hernepitoisuutta. Erityisesti superfosfaatti vaikutti herneen kasvuun edullisesti.

Mutasuolle perustetun vastaavanlaisen kokeen heinänäytteistä KaILAN (1) suorittaman kemiallisen tutkimuksen perusteella on syytä olettaa, että superfosfaattilannoitus rahkasuollakin lisää heinän fosforipitoisuutta enemmän kuin thomasfosfaattilannoitus.

\section{$P$ ä $\ddot{a} t$ e $l m$ ät}

Superfosfaattilannoituksella saadaan rahkasuolta sekä viljan- että heinänviljelyssä suuremmat sadot kuin thomasfosfaattia käytettäessä.

Superfosfaattilannoitus parantaa sadon laatua enemmän kuin thomasfosfaatti vaikuttamalla edullisesti mm. palkokasvien kasvuun.

\section{K I R J A L L I S U T T A}

(1) Karla, A. 1958. Effect of various kinds of phosphorus fertilizers on peat soil. Maatal. tiet. aikak. $30: 213-222$.

(2) Lindberg, H. 1903. Leteensuon kasvillisuus. S. suovilj. yhd. vuosik. 1903: 264-270.

(3) Pessı, Y. 1959. Kivennäismaan vaikutuksesta rahkasuon maanparannusaineena Leteensuon koeaseman pitkäaikaisten kenttäkokeiden perusteella. Summary: On the effect of mineral soil as a soil improving agent on Sphagnum bogs on the basis of prolonged field tests at Leteensuo Experimental Station. Acta agr. fenn. 94. 14: 241-268.

(4) Pessi, Y. 1960. Fertilization of Sphagnum bogs, on the basis of certain field experiments at Leteensuo. Maatal. tiet. aikak. 32: 144-157.

(5) Rindell, A. 1903. Geologisessa mielessä huomattava tulos Leteensuon tutkimisesta. S. suovilj. yhd. vuosik. 1903: $271-275$.

(6) Takala, M. 1961. Super- thomas- ja hienofosfaatin vaikutuksesta mutasuolla. Maatal. tiet. aikak. 33: $57-64$.

(7) Vesikrvi, A. 1937. Superfosfaatti- ja thomasfosfaattilannoitteiden vertailu rahkasuomaalla. Ibid. 1937: $184-213$.

\section{S U M M A R Y :}

ON THE EFFECT OF SUPERPHOSPHATE AND BASIC SLAG ON SPHAGNUM BOG

MaUri TAKala

Society of Peat Cultivation, Experiment Station Leteensuo

At Leteensuo Experiment Station a trial to compare the effects of superphosphate and basic slag on Sphagnum soil was started in 1926. The test area consisted of a Sphagnum fuscum pine bog. The thickness of the unhumified Sphagnum peat layer was about 2 metres. Under this layer there is a layer of Sphagnum-Carex peat and Carex peat so that the thickness of the whole peat layer is more than 3 metres.

The test area was reclaimed in summer 1924 and clayed in winter $1926\left(200 \mathrm{~m}^{3} / \mathrm{ha}\right)$. It was ditched leaving the strips between the open ditches 20 metres wide. The test area contains 2 strips. In $1926-27$ the test area was treated with stable manure and fen peat in equal amounts, altogether $50 \mathrm{~m}^{3} / \mathrm{ha}^{2}$ 
Manuring was renewed with similar amounts in 1935. One of the strips was limed with slaked lime $4000 \mathrm{~kg} / \mathrm{ha}$ in $1926-27,2000 \mathrm{~kg} / \mathrm{ha}$ in 1935 and with limestone dust $2000 \mathrm{~kg} / \mathrm{ha}$ in 1940.

Basic slag was applied in amounts containing citric acid soluble $\mathrm{P}_{2} \mathrm{O}_{5}$ in the same ratio as the superphosphate contained ammonium citrate soluble $\mathrm{P}_{2} \mathrm{O}_{5}$.

The whole test area was treated yearly with $40 \%$ potassium salt $250 \mathrm{~kg} / \mathrm{ha}$ and with calcium nitrate $200-300 \mathrm{~kg} / \mathrm{ha}$.

The original plan was changed so that in 1940,1942 and $1949-52$ the test area was not treated with phosphate fertilizers. In 1948 the basic slag was replaced by a corresponding amount of hyperphosphate. The test results starting from 1948 are shown separately in Table 5 .

According to the test results the effect of superphosphate on cereals and ley on Sphagnum bog was better than the effect of basic slag. Superphosphate improves the quality of the crop more than basic slag and has a favourable effect among others on the growth of leguminous plants.

Liite I. Superfosfaatin ja thomasfosfaatin vertaileva koe rahkasuolla. Sadot vuosittain $\mathrm{kg} / \mathrm{ha}$.

$$
\mathrm{I}=\text { kalkitsematon, } \mathrm{II}=\text { kalkittu. }
$$

Appendix 1. Comparative test between superphosphate and basic slag on Sphagnum bogs. Annual yields, kg per ha. $I=$ unlimed, $I I=$ limed.

\begin{tabular}{|c|c|c|c|c|c|c|c|c|c|c|c|}
\hline & & & & & & & & & & \\
\hline & & & & & & & \multicolumn{4}{|c|}{$\begin{array}{c}\text { Lannoitus } \\
\text { Fertilizer applied }\end{array}$} & \multirow[b]{2}{*}{$2 \mathrm{Ptf}$} \\
\hline & & & & & & & 0 & Psf & $\mathrm{Ptf}$ & 2Psf & \\
\hline \multirow[t]{4}{*}{1926} & Kaura & jyviă & - Oats & & $\ldots \ldots$ & grain I & 1695 & 1910 & 1835 & 1960 & 1645 \\
\hline & & & & & & II & 1425 & 1685 & 1505 & 1815 & 1600 \\
\hline & & olkia & - & & & straw I & 2605 & 2790 & 2765 & 2890 & 2505 \\
\hline & & & & & & II & 2025 & 2515 & 2170 & 2785 & 2300 \\
\hline \multirow[t]{4}{*}{1927} & Hernekaura & jyviä & - Peas & and & oats & grain I & 2150 & 2315 & 2277 & 2310 & 2273 \\
\hline & & & & & & II & 2045 & 2117 & 2173 & 2165 & 2232 \\
\hline & & olkia & - & & & straw I & 4200 & 4585 & 4423 & 4440 & 4277 \\
\hline & & & & & & II & 3705 & 4183 & 3902 & 4135 & 4468 \\
\hline \multirow[t]{2}{*}{1928} & 1. nurmi & heiniä & $-1 s t y e$ & ear $l$ & ley & hay & 2888 & 5819 & 3911 & 6039 & 3894 \\
\hline & & & & & & II & 2668 & 7315 & 3438 & 7948 & 3823 \\
\hline \multirow[t]{2}{*}{1929} & 2. & , & $-2 n d$ & . & . & I & 2695 & 5913 & 3878 & 6380 & 4263 \\
\hline & & & & & & II & 3410 & 6683 & 5088 & 7178 & 4263 \\
\hline \multirow[t]{2}{*}{1930} & 3. & . & $-3 r d$ & " & , & I & 1018 & 3218 & 2008 & 3423 & 2063 \\
\hline & & & & & & II & 1788 & 3960 & 2118 & 3990 & 2310 \\
\hline \multirow[t]{2}{*}{1931} & 4. & , & $-4 t h$ & - & , & I & 925 & 3425 & 1875 & 3475 & 2175 \\
\hline & & & & & & II & 1600 & 4250 & 2425 & 4125 & 2725 \\
\hline \multirow[t]{4}{*}{1932} & Kaura & jyviä & - Oats & & & grain I & 985 & 1878 & 1603 & 1820 & 1598 \\
\hline & & & & & & II & 720 & 1628 & 1045 & 1593 & 1325 \\
\hline & & olkia & - & & & straw I & 1930 & 3415 & 2655 & 3280 & 2960 \\
\hline & & & & & & II & 1480 & 2925 & 1890 & 2640 & 2420 \\
\hline 1933 & Kesanto & & & & & & & & & & \\
\hline \multirow[t]{4}{*}{1934} & Ruis & jyviä & - Rye & & & grain I & 801 & 1225 & 1040 & 1129 & 960 \\
\hline & & & & & & II & 507 & 1065 & 725 & 1165 & 828 \\
\hline & & olkia & - & & & straw I & 1996 & 3582 & 3285 & 3879 & 3380 \\
\hline & & & & & & II & 1328 & 3028 & 1843 & 3410 & 2220 \\
\hline \multirow[t]{4}{*}{1935} & Hernekaura & jyviä & - Peas & and & oats & grain I & 1962 & 1973 & 2077 & 2048 & 1935 \\
\hline & & & & & & II & 1990 & 2072 & 2185 & 2192 & 2115 \\
\hline & & olkia & - & & & straw I & 5363 & 5350 & 5543 & 5490 & 5435 \\
\hline & & & & & & II & 5280 & 5273 & 5593 & 5603 & 5475 \\
\hline
\end{tabular}




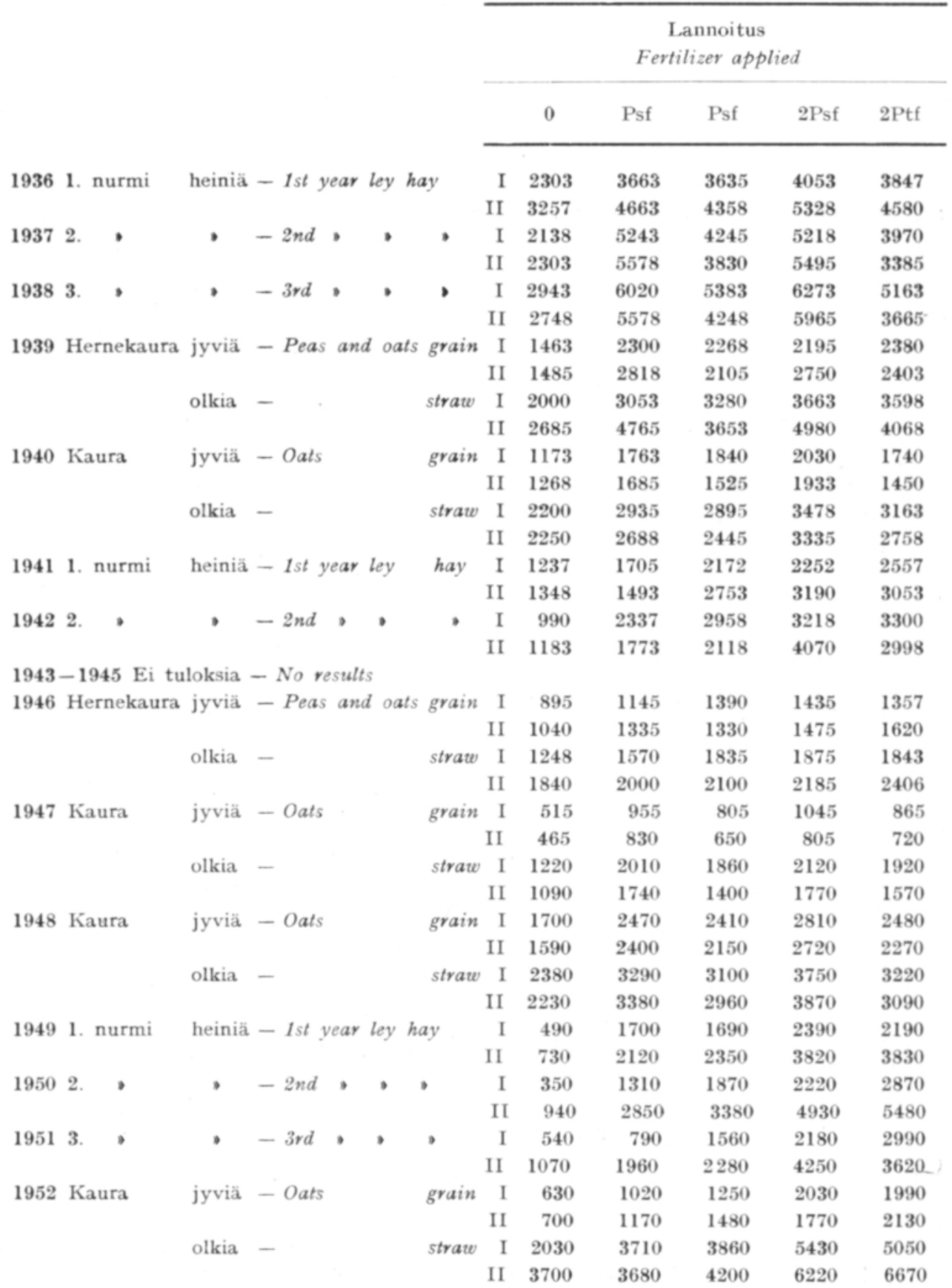

